\section{Talented Softballer Puts Others First}

A determination to help disadvantages people throughout Queensland participate in softball has seen Griffith leisure studies graduate Kelly McKellar turn her back on an opportunity to work and study in the United States.

Kelly, who graduated in September, has already experienced her share of overseas travel with a trip to China as part of the Australian Open Women's Softball Team.

It was during her time in Beijing in 1992 that Kelly was offered a sports scholarship with the Oklahoma
City University, which she accepted. Last year, she returned to Brisbane, with only one semester remaining to finish a Bachelor of Science and Sociology degree at the US university.

'Under the terms of the scholarship, I felt my first commitment was to my softball coach as he was paying for my education,' she explained. 'As a result, with my playing commitments there wasn't enough time left to complete the degree. It was frustrating, but the university suggested it might be able to make arrangements for me to come back and finish my studies.'

Kelly admitted the opportunity to return to Oklahoma had now come through, but it now

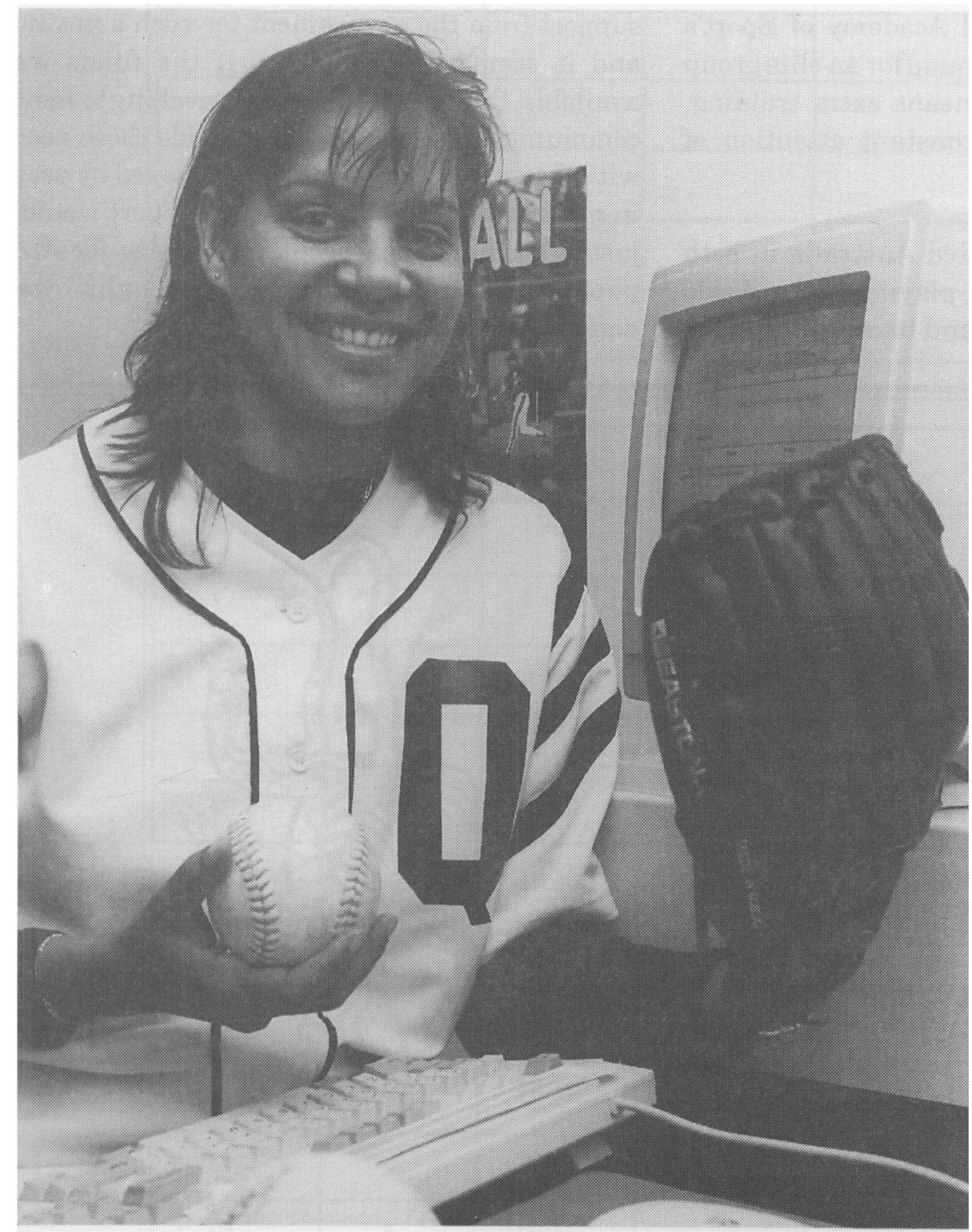

Griffith graduate Kelly McKellar - working to give others the same opportunities in softball. appears unlikely the 23-year-old will turn her back on her efforts to help Queensland Indigenous and disadvantage people get access to her sport. Since completing her leisure studies degree at Griffith University earlier this year, Kelly has been working fulltime with the Queensland Softball Association preparing a policy statement for Indigenous participation in sport.

'I spent a month with the Association as part of my Griffith requirements and towards the end of that work experience, they offered me a 12 month contract to prepare policies and develop strategies to increase access of the sport to Indigenous people,' Kelly said. 'Because I am Aboriginal, I would really like to help 
Indigenous people get the same opportunity that I have been given to enjoy softball. I am so involved in the work at the moment that it is unlikely I'll go back to the United States, despite the opportunity to finish the degree.'

Kelly's time in the American city was marked by freezing weather, tornados, and the bombing of a US government building in which scores of people were killed. 'We weren't in the tornado zone but they were a talking point,' she said. 'Apart from the freezing weather during winter, the worst experience was the bombing because we were only about five minutes away from where it happened. I have to admit it was a scary experience.'

Since returning to Australia, Kelly has quickly returned to representative softball and is now a member of the Queensland Academy of Sport's Squad. Involvement in the squad for an elite group of Queensland softballers means extra training, medical support and the constant attention of selectors.

Kelly has already represented Australia in both under 19 and Open softball, playing in the World Series in Adelaide in 1991, and touring China the following year. Now she is back in the local scene, Kelly is hoping to make the Queensland Open Softball Team, which will be selected later this year.

Her long-range sporting goals include a position in the Australian team, and a chance to compete at the Sydney Olympics in 2000. Despite these exciting possibilities, Kelly's mind is firmly set on giving something back to the community, although there is some uncertainty about what will happen when her position with the Queensland Softball Association finishes next year.

'I would really like to see the Association establish the position of an Indigenous Development Officer, but they simply don't have the finances,' she said. 'They have encouraged me to seek funding and support from the government for such a position, and it seems a good idea. If the funds were available, the job would involve travelling to remote communities and working to provide those people with the same access to sport as enjoyed by people in metropolitan areas. And the support wouldn't just be for Indigenous people, it would be for all the people in those communities who were disadvantaged.'

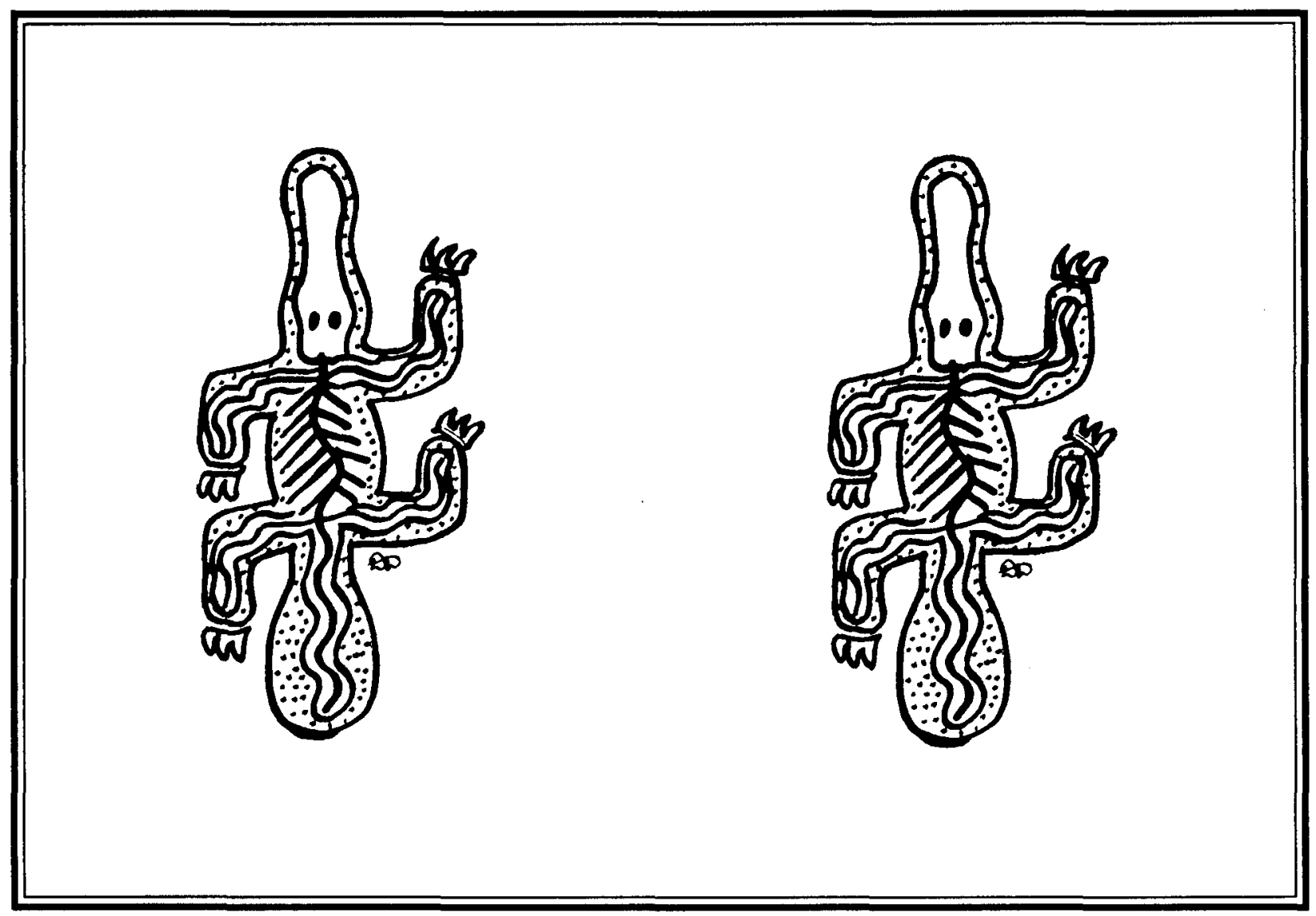

